\title{
Identification of cellular deoxyhypusine synthase as a novel target for antiretroviral therapy
}

\author{
Ilona Hauber, ${ }^{1}$ Dorian Bevec, ${ }^{2}$ Jochen Heukeshoven, ${ }^{1}$ Friedrich Krätzer, ${ }^{2}$ Florian Horn, ${ }^{3}$ \\ Axel Choidas, ${ }^{2}$ Thomas Harrer, ${ }^{4}$ and Joachim Hauber ${ }^{1}$ \\ ${ }^{1}$ Heinrich-Pette-Institute for Experimental Virology and Immunology, Hamburg, Germany. ${ }^{2}$ Axxima Pharmaceuticals AG, Munich, Germany. \\ ${ }^{3}$ Institute for Clinical and Molecular Virology and ${ }^{4}$ Immunodeficiency Unit, Department of Medicine III, University Erlangen-Nürnberg, Erlangen, Germany.
}

\begin{abstract}
The introduction of highly active antiretroviral therapy (HAART) has significantly decreased morbidity and mortality among patients infected with HIV-1. However, HIV-1 can acquire resistance against all currently available antiretroviral drugs targeting viral reverse transcriptase, protease, and gp41. Moreover, in a growing number of patients, the development of multidrug-resistant viruses compromises HAART efficacy and limits therapeutic options. Therefore, it is an ongoing task to develop new drugs and to identify new targets for antiretroviral therapy. Here, we identified the guanylhydrazone CNI-1493 as an efficient inhibitor of human deoxyhypusine synthase (DHS). By inhibiting DHS, this compound suppresses hypusine formation and, thereby, activation of eukaryotic initiation factor $5 \mathrm{~A}$ (eIF-5A), a cellular cofactor of the HIV-1 Rev regulatory protein. We demonstrate that inhibition of DHS by CNI-1493 or RNA interference efficiently suppressed the retroviral replication cycle in cell culture and primary cells. We show that CNI-1493 inhibits replication of macrophage- and $T$ cell-tropic laboratory strains, clinical isolates, and viral strains with high-level resistance to inhibitors of viral protease and reverse transcriptase. Moreover, no measurable drug-induced adverse effects on cell cycle transition, apoptosis, and general cytotoxicity were observed. Therefore, human DHS represents a novel and promising drug target for the development of advanced antiretroviral therapies, particularly for the inhibition of multidrug-resistant viruses.
\end{abstract}

\section{Introduction}

The efficient inhibition of the HIV-1 life cycle by highly active antiretroviral therapy (HAART) has been shown to profoundly improve the morbidity and mortality among HIV-1-infected patients (1-4). Current routine drug regimens typically consist of various combinations of compounds that target the viral proteins reverse transcriptase, protease, and gp41 (5). Unfortunately, in a growing number of patients long-term HAART is accompanied by significant adverse side effects including mitochondrial toxicity, lipodystrophy, diabetes mellitus, and osteoporosis (5). In addition, HIV-1 can acquire resistance to all known inhibitors of reverse transcriptase, protease, and gp41, and transmission of multidrug-resistant HIV strains is becoming a growing problem among newly infected persons. In fact, a recent study reported that the proportion of new HIV infections that involve antiretroviral drug-resistant virus increased significantly in North America over the previous years (6). Therefore, it is an ongoing task to develop new drugs for targeting drug-resistant viruses. As multidrug-resistant viruses frequently exhibit broad cross-resistance to inhibitors of reverse transcriptase and protease, it is also important to identify new targets for inhibition of viral replication (7).

The formation of progeny viruses requires multiple intracellular interactions of both viral components and host cell factors. The

Nonstandard abbreviations used: bDNA, branched DNA; DHS, deoxyhypusine synthase; eIF-5A, eukaryotic initiation factor 5A; HAART, highly active antiretroviral therapy; LTR, long-terminal repeat; MKK, MAPK kinase; MTT, methylthiazoletetrazolium salt; RNAi, RNA interference; SEAP, secreted alkaline phosphatase; siRNA, small interfering RNA; snRNA, small nuclear RNA.

Conflict of interest: The authors have declared that no conflict of interest exists.

Citation for this article: J. Clin. Invest. 115:76-85 (2005)

doi:10.1172/JCI200521949. identification of these critical host cell factors may therefore provide novel cellular drug targets for the development of compounds that are potentially capable of inhibiting HIV-1.

HIV-1 replication depends on the action of the viral regulatory protein Rev (reviewed in ref. 8). Eukaryotic initiation factor 5A (eIF-5A) has been previously reported to be a cellular cofactor of the Rev pathway $(9,10)$. In the present study we investigated possibilities to block HIV-1 replication by inhibiting human deoxyhypusine synthase (DHS), an enzyme that is required for eIF-5A biological activity. We show that this cellular factor constitutes a new target for inhibition of HIV-1, including HAART-resistant strains.

\section{Results}

The guanylhydrazone CNI-1493 is a novel inbibitor of DHS. eIF-5A is the only known cellular protein that contains the amino acid hypusine [ $N^{\varepsilon}$-(4-amino-2-hydroxybutyl)-lysine], a modification that appears to be required for eIF-5A activity $(11,12)$. The hypusine formation is a highly specific, spermidine-dependent posttranslational reaction that is catalyzed by 2 enzymes (11). In the first step, the aminobutyl moiety of spermidine is transferred to the $\varepsilon-\mathrm{NH}_{2}$ group of a single lysine residue at position 50 within the human 154-amino acid eIF-5A protein (Figure 1A). This reaction is catalyzed by DHS. The resulting eIF-5A intermediate is then further modified by deoxyhypusine hydroxylase, generating the active form of eIF-5A. The most potent inhibitors of DHS so far described are structural derivatives of spermidine (13) that have been reported to exert antiproliferative effects in cell lines (14-16). In order to develop novel types of DHS inhibitors, we recently identified the multivalent guanylhydrazone CNI-1493 by high-throughput screening assay to be a small-molecular weight inhibitor of human DHS in vitro (17). 
A

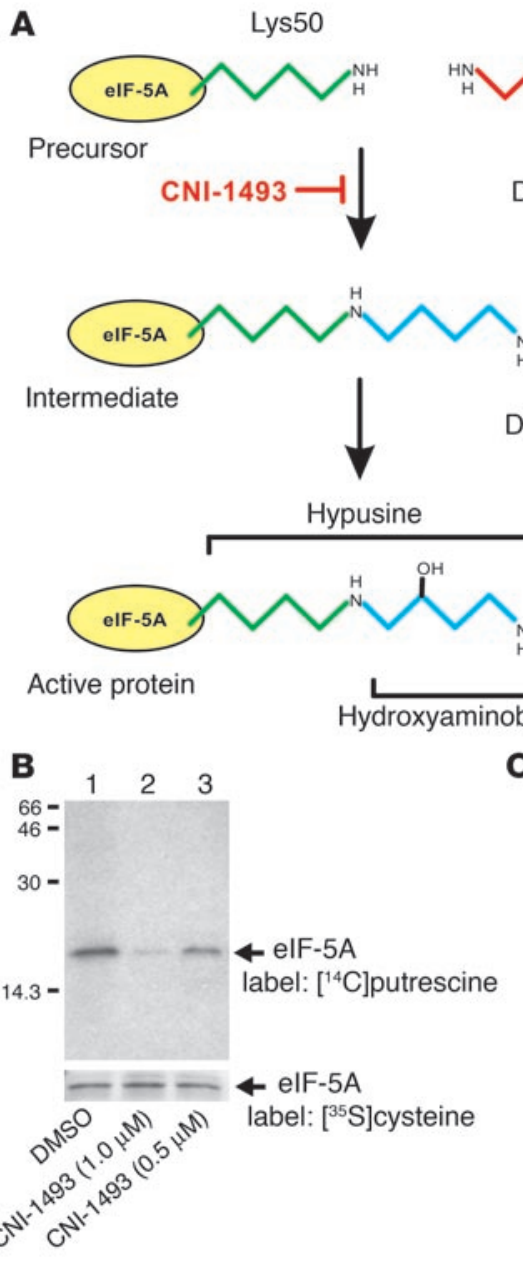

Spermidine

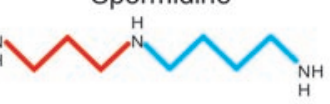

DHS

$\mathrm{DHH}$

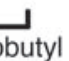
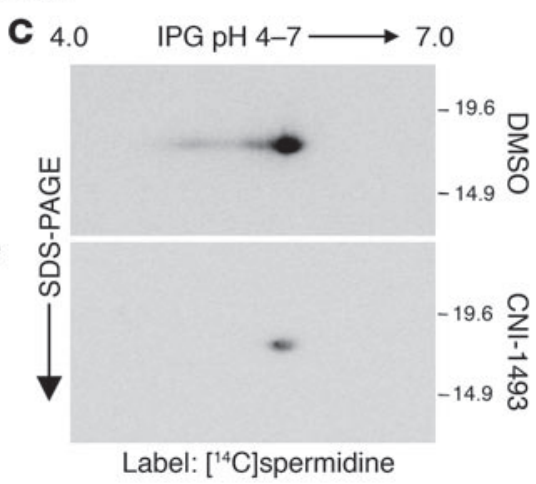

Figure 1

Inhibition of hypusine formation in elF-5A by interfering with DHS activity. (A) Schematic representation of the pathway of elF-5A biosynthesis. Hypusine is required for the biological activity of the protein. The conversion of a specific lysine residue (Lys50) into the unusual amino acid hypusine occurs in 2 posttranslational reactions that are mediated by the enzymes DHS and deoxyhypusine hydroxylase $(\mathrm{DHH}$; see text for details). DHS is a target of experimental low-molecular weight drugs, such as the multivalent guanylhydrazone CNI-1493. (B) CNI-1493 inhibits hypusine formation in elF-5A in vivo. Jurkat cells were metabolically labeled using either $\left[{ }^{14} \mathrm{C}\right]$ putrescine or $\left[{ }^{35} \mathrm{~S}\right]$ cysteine in the presence of either DMSO (solvent control, lane 1) or $\mathrm{CNI}-1493(1.0 \mu \mathrm{M}$, lane 2; $0.5 \mu \mathrm{M}$, lane 3). Equal amounts of the various radiolabeled cellular extracts were then subjected to elF-5A-specific immunoprecipitation analysis and analyzed by SDS-PAGE and autoradiography. Molecular mass standards are indicated in $\mathrm{kDa}$. (C) Two-dimensional electrophoresis of total proteins from PM1 cells that were metabolically labeled using $\left[{ }^{14} \mathrm{C}\right]$ spermidine in the presence of either DMSO (upper panel) or $\mathrm{CNI}-1493$ (1.0 $\mu \mathrm{M}$; lower panel). Protein separation was performed, using equal amounts of the radiolabeled extracts, by isoelectric focusing in the first dimension on an immobilized linear $\mathrm{pH}$ gradient (IPG) from pH 4.0 to 7.0 , which was followed by SDS-PAGE separation in the second dimension. Only molecular mass of less than $25.0 \mathrm{kDa}$ is shown in autoradiographs. No radioactive protein spots were detected elsewhere. Molecular mass standards are indicated in $\mathrm{kDa}$ on the right.
CNI-1493 ( $N, N^{\prime}$-bis[3,5-bis[1(aminoiminomethyl)hydrazonoethyl] phenyl]decanediamide tetrahydrochloride) is an experimental drug that is currently in phase II clinical trials for Crohn disease. It has been shown to inhibit synthesis of TNF in monocytes/macrophages by somehow suppressing translation efficiency (18). In addition, this compound has been reported to prevent the phosphorylation of $\mathrm{p} 38$ MAPK, and this effect may interfere with HIV-1 replication $(19,20)$.

In the present study we tested the effect of CNI-1493 on DHS activity in vivo by eIF-5A-specific immunoprecipitation analysis using cellular extracts derived from Jurkat $\mathrm{T}$ cells that were metabolically labeled using either $\left[{ }^{14} \mathrm{C}\right]$ putrescine, a metabolic precursor of spermidine, or $\left[{ }^{35} \mathrm{~S}\right]$ cysteine. As visualized by autoradiography (Figure 1B), addition of CNI-1493 to the cell cultures clearly inhibited hypusine modification of eIF-5A in a dose-dependent fashion (lanes 2 and 3, upper panel), unlike in the control experiment, in which DMSO alone (a solvent for CNI-1493) was present (lane 1). Importantly, no inhibitory effect of CNI-1493 on de novo eIF-5A synthesis was observed in the control experiment (Figure $1 \mathrm{~B}$, lower panel), using $\left[{ }^{35} \mathrm{~S}\right]$ cysteine. Next, we analyzed total cellular extracts of $\left[{ }^{14} \mathrm{C}\right]$ spermidine-labeled PM1 cells by 2-dimensional gel electrophoresis and subsequent autoradiography. In agreement with the literature, and as shown in Figure 1C (upper panel), this type of labeling resulted exclusively in the detection of the unique hypusine-containing protein eIF-5A and its minor isoforms $(11,21)$. Again, addition of CNI-1493 to the cell cultures clearly inhibited the labeling of eIF-5A (Figure 1C, lower panel). Taken together, these data demonstrate that the guanylhydrazone CNI-1493 is a novel and potent inhibitor of DHS.

Effect of DHS inbibition on replication of HIV-1. Because the hypusinecontaining protein eIF-5A has been shown to be a critical cofactor of the HIV-1 Rev regulatory protein (reviewed in ref. 22), we hypothesized that treatment of infected cells with CNI-1493 may block HIV-1 replication. Therefore, we first analyzed the effect of CNI1493 on the replication of HIV-1 laboratory strains. For this, PM1 cells were infected with the macrophage-tropic strain $\mathrm{BaL}$, or the $\mathrm{T}$ cell-tropic HIV-1 strain NL4/3. After infection, cells were washed, resuspended, and cultured in the presence of CNI-1493 (dissolved in DMSO), or in medium supplemented with DMSO as a control for the calculation of inhibition of virus replication. At days 3, 6, and 9 after infection, the culture medium was replaced and cells were split. Viability of the cells (measured by methylthiazoletetrazolium salt [MTT] assay) and p24 antigen levels were determined at days 6 and 12. As shown in Figure 2, $1.0 \mu \mathrm{M}$ CNI-1493 blocked both the macrophage-tropic strain $\mathrm{BaL}$ and the $\mathrm{T}$ cell-tropic strain NL4/3 very efficiently, reaching virus inhibition rates that ranged from $82 \%$ to $98 \%$ (upper panels). It is also important to note that at this drug concentration no significant differences in cell viability were detected in the cultures (Figure 2, lower panels).

For further characterization of the antiviral effect observed, we next extended our studies to clinical HIV-1 isolates. PBMCs from 

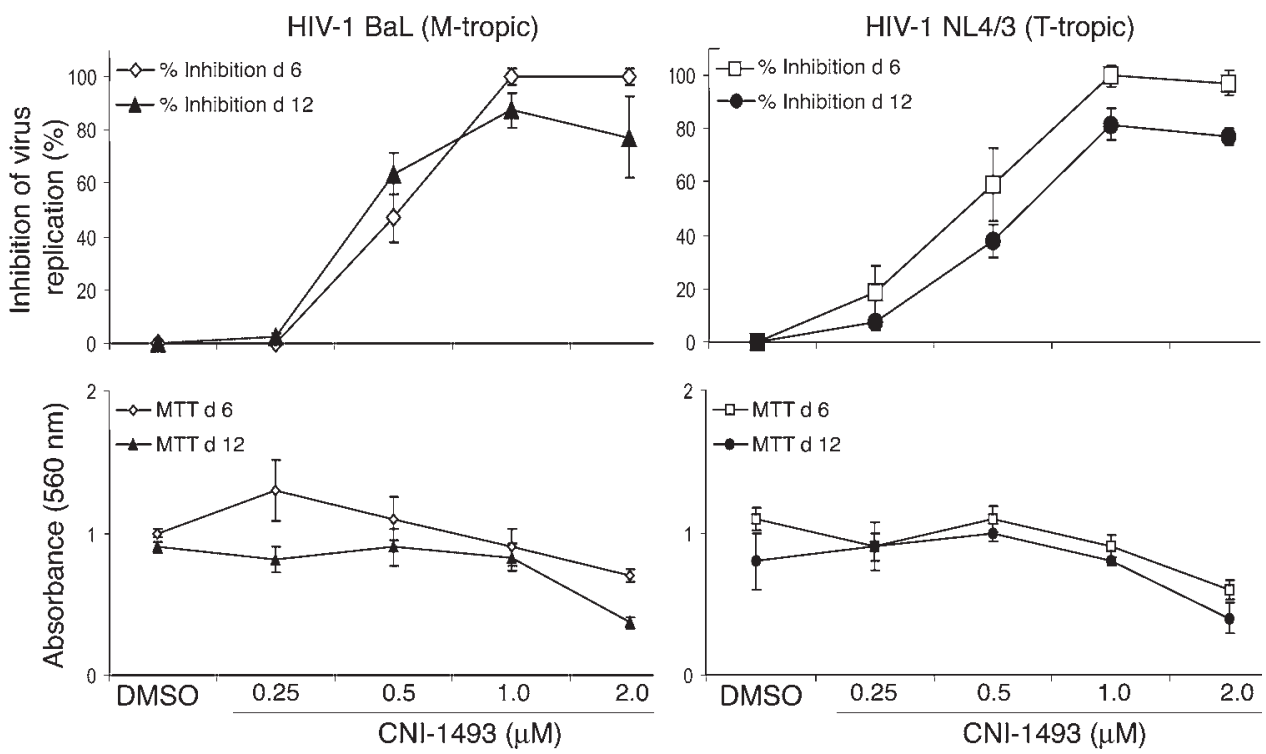

\section{Figure 2}

Inhibition of macrophage-tropic (Mtropic) and $\mathrm{T}$ cell-tropic (T-tropic) HIV-1. PM1 cells were infected with HIV-1 BaL or NL4/3. Infected cells were cultured in the presence of the indicated concentrations of $\mathrm{CNI}-1493$, or with DMSO alone (control). The culture medium was changed at days 3,6 , and 9. p24 antigen levels and cell viability were determined at days 6 and 12. The percentage of inhibition of virus replication as compared with replication in the control culture without drug, which was arbitrarily set at $100 \%$, is shown in the upper panels. MTT assays (Roche Diagnostics $\mathrm{GmbH}$ ) from the same cultures are shown in the lower panels.
HIV-1-infected patients were cultured for 14 days in the presence of CNI-1493 (final concentration: $0.5 \mu \mathrm{M}$ or $1.0 \mu \mathrm{M}$ ) or without inhibitor (DMSO control). The culture medium was replaced every 3 days. Once a week, each culture was split 1:1 and feeder PBMCs (isolated from healthy donors) and IL-2 were added. At day 14, virus replication was determined by $\mathrm{p} 24$ antigen ELISA and/or branched DNA (bDNA) assay. Analysis of cell viability again revealed no significant differences between drug-treated and untreated cultures. Approximately $75-80 \%$ of the cells in these cultures were viable. The observed antiviral effect in these primary cells was more pronounced than those in cell lines. CNI-1493 clearly inhibited the various clinical virus isolates (Figure 3). Obviously, treatment of the cells with CNI-1493 repeatedly resulted in HIV-1 inhibition rates of greater than 90\% (Figure 3, patients 1, 3, and 4). In 1 experiment, however, only partial inhibition of virus replication was achieved (patient 2; inhibition rate at $1.0 \mu \mathrm{M}: 54 \%$ ). At this time we do not know the reason for this. However, it has been previously shown that CNI-1493 binds to circulating fetuin and that this complex is taken up by the cell (19). It can therefore not be ruled out that a potential polymorphism in the gene encoding the respective asialoglycoprotein receptor may influence the efficacy of CNI-1493 in patients.

We also performed long-term infection experiments over a period of 10 weeks using infected PBMCs from another AIDS patient. The obtained data clearly demonstrated extended periods of inhibition of virus replication (greater than 95\%) with no apparent loss of drug sensitivity (supplemental data available online with this article; doi:10.1172/JCI200521949DS1).

In order to gain insight into the kinetics of CNI-1493 action, we next performed a drug wash-out experiment. PM1 cells were infected with HIV-1 BaL as described above and cultured in the presence of CNI-1493 at a concentration of $0.5 \mu \mathrm{M}$. At day 12 after infection, the culture was split 1:1. One of these cultures was further incubated in the presence of $0.5 \mu \mathrm{M}$ CNI-1493, while the remaining one was washed and cultured for another 12 days in the presence of the drug solvent DMSO only (control). The culture medium was replaced at days $2,5,7,10$, and 12 before the drug was removed and at days 2, 5, 7, and 9 after cell splitting. Again, viability of the cells and p24 antigen levels were determined as before at the indicated days (see Figure 4A). As shown, antivi- ral effects increased continuously during the initial days of drug treatment, reaching the greatest levels of inhibition between days 7 and 12 after infection. The number of living cells in the culture increased steadily during this period. Following splitting of the cell culture at day 12 after infection, maximal inhibition of virus replication remained constant in the presence of CNI-1493 for another 12 days, the time point when the experiment was finally terminated. In sharp contrast, however, withdrawal of CNI-1493 resulted in breakthrough of virus replication in the respective culture around day 7 after drug removal. Clearly, more viable cells were observed in the protected culture as compared with the cell culture in which virus replication was not repressed. These data demonstrate that the kinetics of CNI-1493 activity is rather slow, requiring approximately a full week until significant anti-HIV-1 effects can be observed. This suggests that the intracellular pool of hypusine-modified eIF-5A is exchanged at relatively slow rates

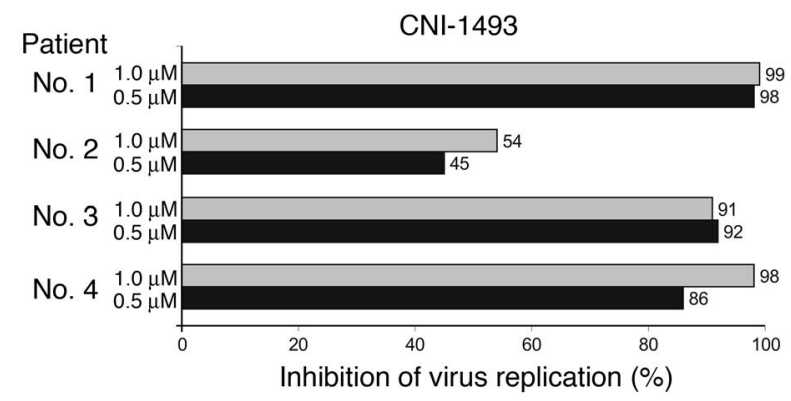

Figure 3

Inhibition of clinical HIV-1 isolates. PBMCs from HIV-1-infected patients were cultured in the presence of $\mathrm{CNI}-1493$. The culture medium was changed every 3 days. Every week, each culture was split 1:1, and fresh feeder PBMCs from 4 healthy donors, treated with PHA-P $(6 \mu \mathrm{g} /$ $\mathrm{ml}$ phytohemagglutinin) and PB ( $1 \mu \mathrm{g} / \mu \mathrm{l}$ polybrene) and preincubated in $\mathrm{CNI}-1493$ for 4 days, were added along with recombinant IL-2. At day 14 , cell counts, cell viability, and p24 antigen and/or bDNA levels were determined (cell counts ranged from $0.9 \times 10^{6}$ to $1.1 \times 10^{6}$ cells per milliliter; in all cultures tested, at least $80 \%$ of the cells were viable). The percentage of inhibition of virus replication as compared with replication in the respective untreated patient cells is shown. 
A
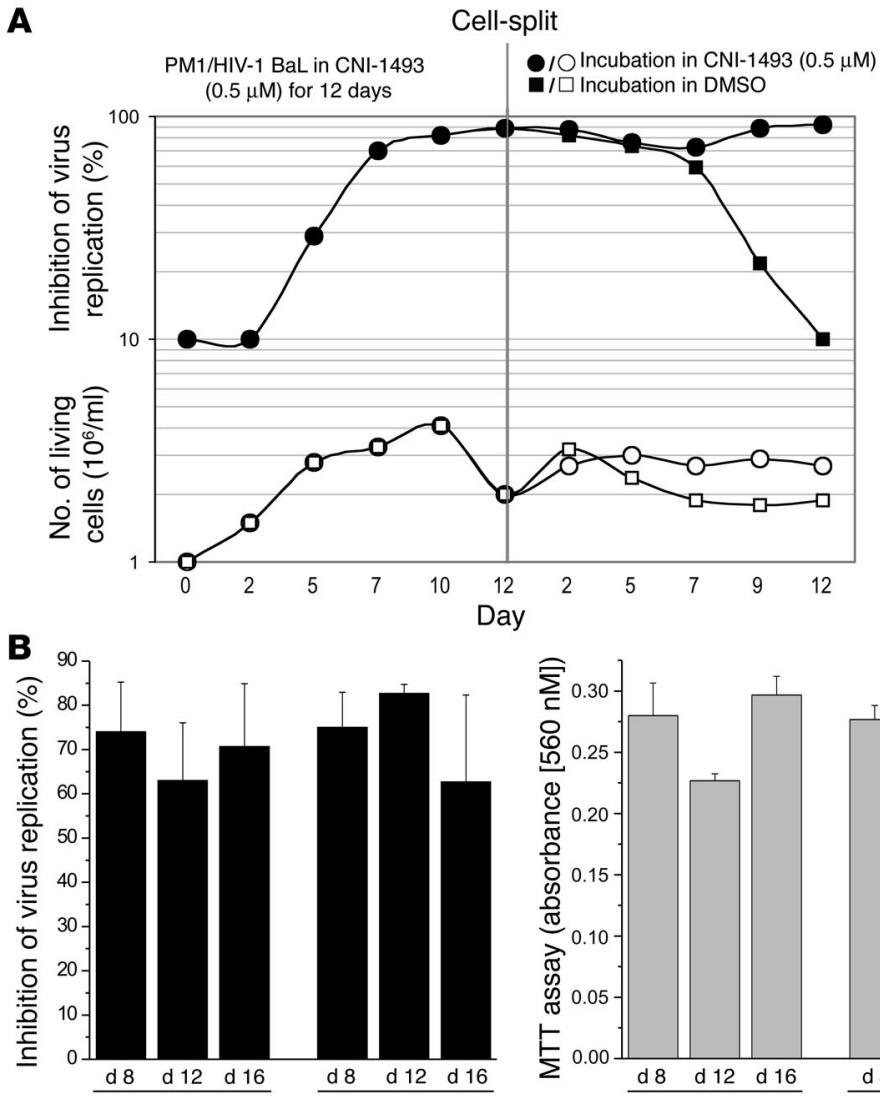

HIV-1 BaL (wk 12) HIV-1 BaL (WT)

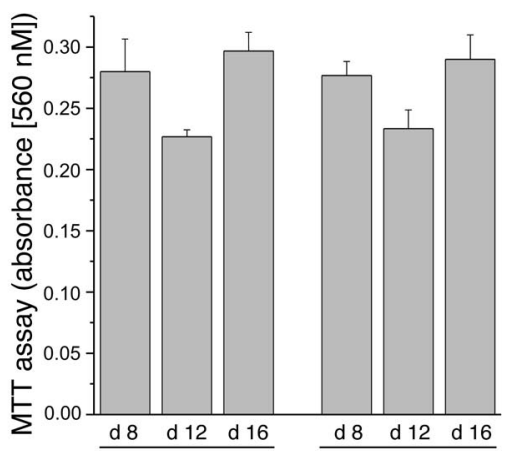

HIV-1 BaL (wk 12) $\overline{H I V-1 ~ B a L ~(W T) ~}$

\section{Figure 4}

Kinetics of HIV-1 inhibition by $\mathrm{CNI}-1493$ and long-term drug exposure. (A) PM1 cells were infected with HIV-1 $\mathrm{BaL}$ and cultured for 12 days in the presence of $\mathrm{CNI}$ 1493 at a concentration of $0.5 \mu \mathrm{M}$. Subsequently, the cells were split in 2 equal halves (Cell-split). One of these cultures was further incubated in culture medium containing $0.5 \mu \mathrm{M} \mathrm{CNI}-1493$ for another 12 days. The other culture was washed with medium and incubated for 12 days in the presence of DMSO (solvent control). The culture medium was changed at days 2, 5, 7, 10, and 12 before the drug was removed, and at days 2 , 5,7 , and 9 after cell splitting. The viability of the cells, cell counts, and p24 antigen levels were determined at the days indicated. (B) HIV-1 BaL-infected PM1 cells were cultured for 12 weeks in the presence of $125 \mathrm{nM}$ $\mathrm{CNI}-1493$. Subsequently, the virus-containing supernatant was used for de novo infection of another batch of PM1 cells, and culturing of these cells, as well as of cells infected with wild-type (WT) HIV-1 BaL, continued for an additional 16 days in the presence of $1.0 \mu \mathrm{M}$ $\mathrm{CNI}-1493$ or DMSO (solvent control). Inhibition of virus replication (in percent; black bars) and drug toxicity (as measured by MTT assay; gray bars) at days 8,12 , and 16 are indicated.

and control siRNA 3 times consecutively over a 6-day period. At day 7, these cultures were infected with HIV-1 NL4/3, and virus replication was monitored by $\mathrm{p} 24$ antigen ELISA at day 3 after infection. In control experiments the effect of siRNA treatment on endogenous DHS mRNA levels was analyzed by RT-PCR. As shown in Figure 5A, transfection of the

by unmodified inactive protein. This notion is in agreement with the findings that the hypusine modification is irreversible and that eIF-5A is characterized by a long half-life of greater than 24 hours in mammalian cells (12).

To address the question of whether resistant isolates arise over time, we next infected PM1 cells with HIV-1 BaL and cultured these cells for 12 weeks at the suboptimal drug level of $125 \mathrm{nM}$ CNI-1493. Ongoing virus replication was observed by detection of p24 antigen in the cellular supernatant over the entire culturing period (not shown). At day 84 after infection, the virus-containing supernatant of this long-term culture, as well as a supernatant containing parental HIV-1 BaL, was used for de novo infection of PM1 cells. The infected cells were washed, split 1:1, and cultured for another 16 days in the presence of $1.0 \mu \mathrm{M}$ CNI-1493 or DMSO only (control). At days 8, 12, and 16 after infection, viability of the cells (by MTT assay) and p24 antigen levels were determined. As shown in Figure 4B, both the wild-type viruses and viruses that were pre-exposed for a prolonged period of time to low drug levels were equally well inhibited by $1.0 \mu \mathrm{M}$ CNI-1493. These data suggest that adaptation of viruses to CNI-1493 is rather unlikely.

As the DHS inhibitor CNI-1493 clearly has anti-HIV properties, the question was raised of whether DHS itself is required for virus replication. If so, the knock-down of this enzyme by RNA interference (RNAi) (23) should also impair the formation of progeny viruses in infected cells. The delayed kinetics of virus inhibition that was previously observed (Figure 4) required the repeated transfection of target cells with small interfering RNA (siRNA). This can be most easily achieved using monolayer cultures. Therefore, we transfected HeLa cells that express the human CD4 protein with DHS-specific cell cultures with DHS siRNA clearly downregulated the corresponding transcripts in these cells, while, in contrast, a control siRNA (SDII) that lacks complementary sequences in the human genome did not negatively affect the abundance of DHS messages. Moreover, gene silencing was accompanied by impaired hypusine modification of eIF-5A as shown by analysis of total $\left[{ }^{14} \mathrm{C}\right]$ spermidine-labeled HeLa cell extracts by 2-dimensional gel electrophoresis (Figure 5B). Importantly, the viral replication capacity was significantly reduced, by $82-88 \%$, in the cultures transfected with DHS-specific siRNA compared with the cultures transfected with control siRNA (Figure 5C, upper panel). Analysis of cytotoxicity (Figure 5C, lower panel) and of integrated proviral DNA (Figure 5D) revealed comparable levels of viable and infected cells in these cultures.

Taken together, these data demonstrated that DHS is indeed a valuable cellular target for interference with HIV-1 replication.

Effect of CNI-1493 on host cells. For this study it was important to demonstrate that the pronounced antiviral effects of CNI-1493 were not due to drug-induced toxic effects on cellular metabolism. We therefore analyzed apoptosis, cell cycle progression, and cell viability in various inhibitor-treated cells (see supplemental data). Furthermore, we demonstrated by detection of extrachromosomal circular viral DNA that CNI-1493 does not block de novo infection (see supplemental data). Taken together, these data demonstrated that the observed antiviral activities of CNI-1493, which were achieved at drug concentrations of $0.5-1.0 \mu \mathrm{M}$, were not caused by deleterious effects of these concentrations of the drug on the host cells. Clearly, at this point we cannot provide more extensive toxicity studies that, for example, define the therapeutic window in more detail. With respect to general toxicity, however, it should 
A
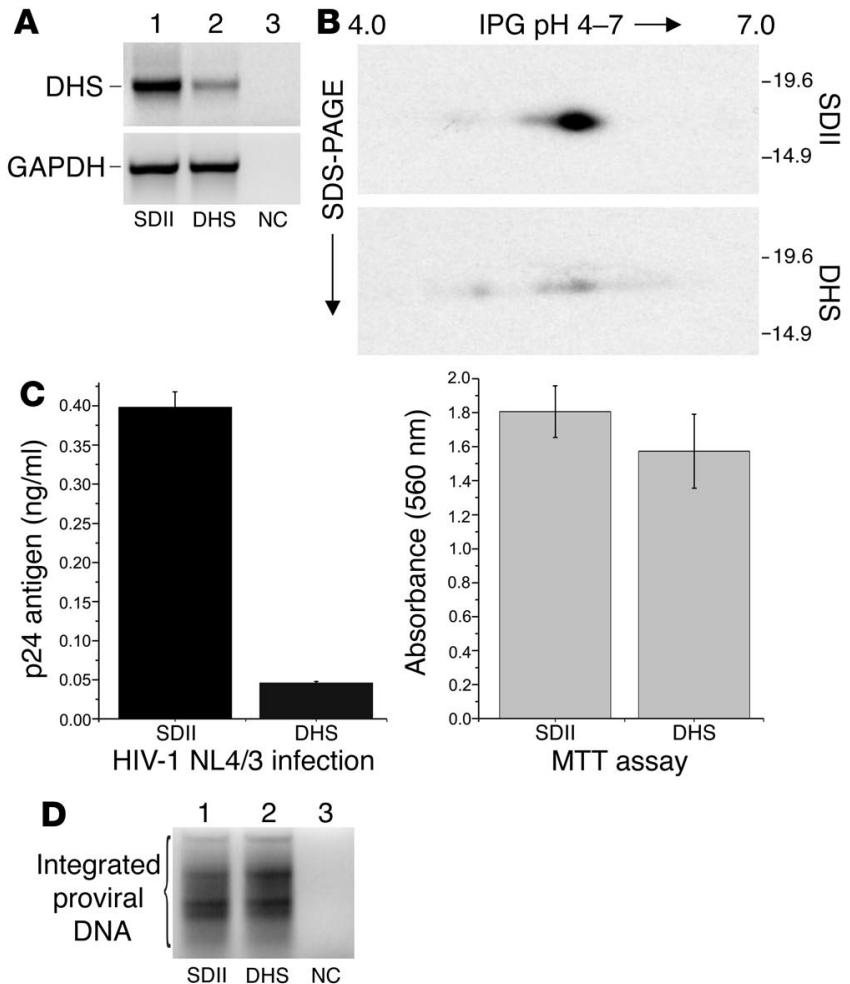

be noted that CNI-1493 is currently being investigated in clinical trials, including an international phase II study in Crohn disease. In these studies patients receive doses of $2-32 \mathrm{mg} / \mathrm{m}^{2}$ (24), corresponding to approximate drug concentrations of $0.8-11.8 \mu \mathrm{M}$, which is well above the range of the CNI-1493 concentrations used in this study to inhibit HIV-1.

Inbibition of Rev trans-activation. HIV-1 replication depends on the cytoplasmic accumulation of unspliced and incompletely spliced viral RNAs, which serve either as templates for translation of the viral structural protein or as viral genomes in the formation of progeny viruses. The transport of these RNAs, from the nuclear site of transcription to the cytoplasmic site of protein synthesis, is mediated by Rev (8). Since evidence has been previously provided that the hypusine-containing protein eIF-5A is required for Rev trans-activation $(9,10)$, the effect of CNI-1493 on Rev activity was analyzed next. We infected PM1 cells with HIV-1 BaL and cultured them in DMSO (solvent control) or $0.8 \mu \mathrm{M}$ CNI-1493. At day 7 after infection, total and cytoplasmic RNAs were isolated and subjected to Northern analysis (Figure 6A). The 3 classes of HIV-1specific RNAs, corresponding to unspliced, singly spliced, and multiply spliced transcripts, were easily detectable in total RNA isolated from DMSO-treated cells (Figure 6A, lane 3). However, analysis of cytoplasmic RNA samples clearly revealed reduced levels of the Rev-regulated unspliced and singly spliced HIV-1 mRNA species in CNI-1493-treated cells (Figure 6A, lane 1 versus lane 2). Quantification of the intensities of the specific bands using a phosphoimager (not shown) showed that the unspliced transcripts were reduced by $58 \%$ and the singly spliced transcripts by $27 \%$ in the drug-treated, as opposed to the untreated, cultures. The detection of the exclusively nuclear U6 small nuclear RNA (snRNA) served as control for the purity of the cytoplasmic samples in these experiments (Figure 6A, lower panel).

\section{Figure 5}

Inhibition of DHS by RNAi. For DHS knock-down, HLCD4-CAT cells, which express the CD4 surface molecule, were repeatedly transfected with either human DHS-specific (DHS) or control scramble II duplex (SDII) siRNAs. (A) RNA was isolated 1 day after the final transfection, followed by first-strand cDNA synthesis. Gene silencing was monitored by DHS-specific PCR. A GAPDH-specific reaction served as internal control. (B) siRNA-treated cells were metabolically labeled using $\left[{ }^{14} \mathrm{C}\right]$ spermidine, and total cell proteins were analyzed by 2 -dimensional electrophoresis and subsequent autoradiography as described in the legend to Figure 1. (C and D) The respective cell cultures were infected with HIV-1 NL4/3 1 day after the final transfection. At day 3 after infection, p24 antigen levels (C, black bars), cell viability (MTT assay; C, gray bars), and integrated proviral DNA (D) were analyzed. $\mathrm{NC}$, negative control reaction.

As an additional assay we analyzed the effect of CNI-1493 on Rev to rescue in trans the replication of a defective HIV-1 provirus specifically mutated in the rev gene (25). As shown in Figure $6 \mathrm{~B}$, coexpression of Rev restored replication of this defective provirus as indicated by the release of amounts of $\mathrm{p} 24$ protein into the supernatant of the respective culture (upper panel). As expected, the Western analysis of a respective cellular extract displayed increased Rev-dependent p55 Gag protein synthesis (lower panel). In contrast, the presence of CNI-1493 inhibited Rev activity in these experiments as demonstrated by a significant decrease in $\mathrm{p} 24$ release, as well as by a reduction in $\mathrm{p} 55^{\mathrm{Gag}}$ synthesis.

As an independent and more rigorous test of whether CNI-1493 indeed directly represses Rev activity, we finally performed specific trans-activation analyses. For this, established Rev- and Tat-dependent reporter vectors (pCMVgagLucRRE and $\mathrm{pBC} 12 / \mathrm{HIV} / \mathrm{CAT}$, respectively) were used in transient transfection experiments $(26,27)$. As shown, CNI-1493 clearly inhibited Rev trans-activation (Figure $6 C$ ), while no negative effect on Tat activity was observed (Figure 6D); this indicates specificity of this compound for the Rev pathway.

Taken together, these data demonstrated that the antiviral effect of CNI-1493 is due to the inhibition of the essential HIV-1 Rev regulatory protein.

Inhibition of multidrug-resistant HIV-1. The occurrence of drug resistance is a major reason for the failure of antiretroviral therapies in HIV-1 infection. Since CNI-1493 targets the biochemical modification on the cellular protein eIF-5A, this compound may prove useful in the inhibition of viruses resistant to conventional antiretroviral drugs (e.g., reverse transcriptase and protease inhibitors). To test this hypothesis, we subjected a representative set of multidrug-resistant viruses to CNI-1493 inhibition studies. The antiretroviral drug profiles of these viruses, as determined by phenotypic resistance testing using the recombinant virus technique (28), are shown in the left panels of Figure 7. In each virogram, the gray center indicates the sensitivity of a nonresistant virus (HIV-1 NL4/3) to the indicated anti-HIV drugs. The red area shows the individual concentrations of these drugs that are required to inhibit replication by $50 \%$ of the tested virus in tissue culture, while the yellow area marks the maximal drug resistance that is detectable in this type of assay. Virus samples displaying, for example, a reduction in inhibitor sensitivity of more than 8-fold are considered fully resistant in this type of assay (29). Thus, the analyzed samples are representative for protease inhibitor-resistant, nucleoside reverse transcriptase inhibitor-resistant, and non-nucleoside reverse transcriptase inhibitor-resistant viruses. Mutations conferring drug resistance were determined by genotypic DNA sequencing (see supplemental data). 

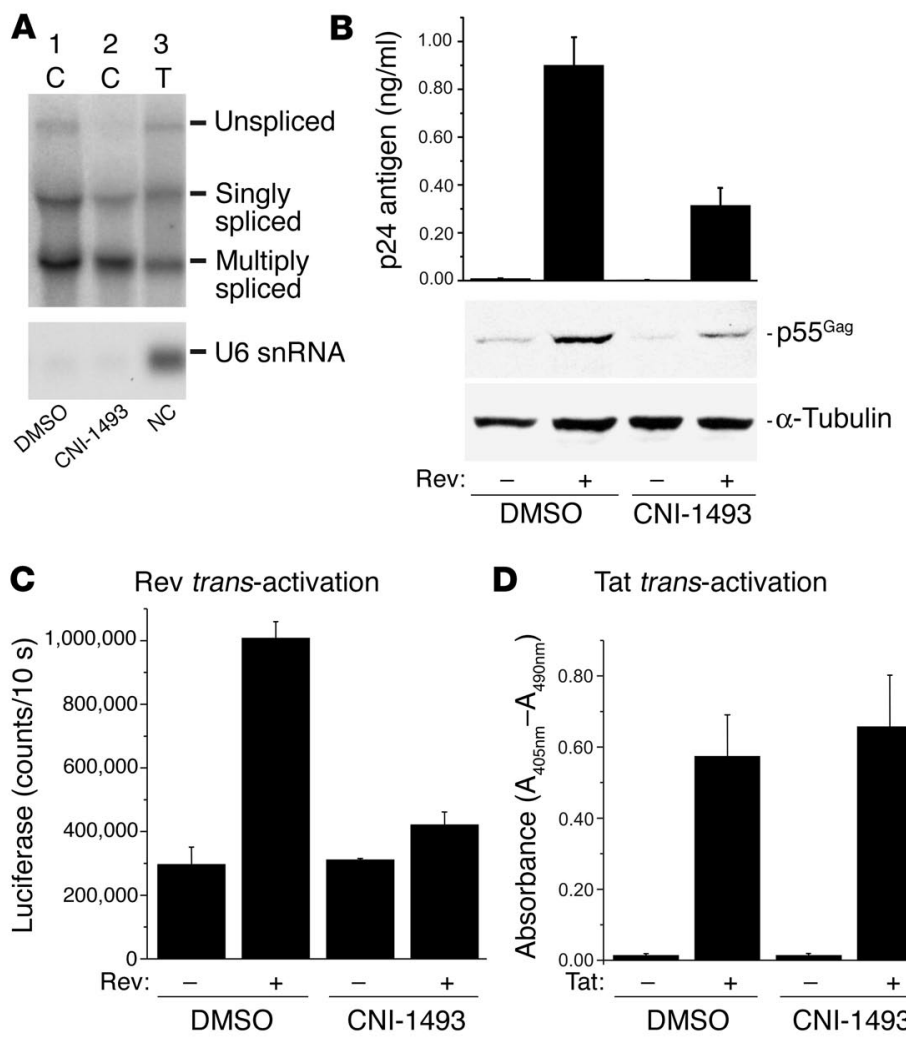

D Tat trans-activation

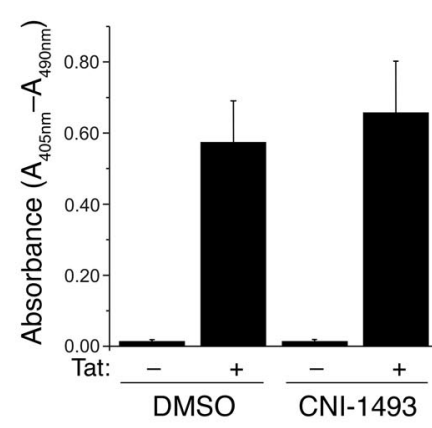

Figure 6

CNI-1493 negatively affects HIV-1 Rev trans-activation. (A) Inhibition of cytoplasmic accumulation of incompletely spliced viral mRNAs. PM1 cells were infected with HIV-1 BaL and subsequently cultured in the presence of either CNI-1493 $(0.8 \mu \mathrm{M})$ or DMSO. Cytoplasmic (C) or total (T) RNA was isolated at day 7 after infection and subjected to HIV-1 mRNA-specific or U6 snRNAspecific Northern analysis. (B) Inhibition of Rev-dependent virus production. HeLa cells were cultured for 7 days in $1.0 \mu \mathrm{M} \mathrm{CNI-1493}$ or DMSO and subsequently cotransfected with a rev-defective proviral DNA, a Rev-expressing vector, or the respective parental plasmid (Rev-deficient control) and a construct expressing constitutively secreted alkaline phosphatase (SEAP). The transfected cell monolayers were further maintained in $1.0 \mu \mathrm{M} \mathrm{CNI}-1493$ or DMSO and analyzed at 60 hours after transfection for levels of p24 antigen. The respective values were adjusted for transfection efficiency by determination of the level of SEAP (upper panel). In addition, total cell protein extracts

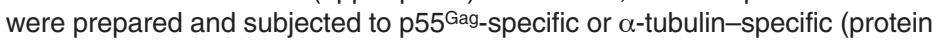
loading control) Western analysis (lower panel). (C) Analysis of Rev transactivation. HeLa cells were cultured in $\mathrm{CNI}-1493$ or DMSO as before and subsequently cotransfected with the Rev-responsive reporter plasmid pCMVgagLucRRE, a Rev-expressing vector, or the respective parental plasmid (Rev-deficient control) and the constitutive internal control vector $\mathrm{pBC12/}$ $\mathrm{CMV} / \beta \mathrm{Gal}$. (D) Analysis of Tat trans-activation. HeLa cells were cultured in $\mathrm{CNI}-1493$ or DMSO as before and subsequently cotransfected with the Tatresponsive reporter plasmid $\mathrm{pBC} 12 / \mathrm{HIV} / \mathrm{CAT}$, a Tat-expressing vector, or the respective parental plasmid (Tat-deficient control) and the constitutive internal control vector $\mathrm{pBC} 12 / \mathrm{CMV} / \beta \mathrm{Gal}$.

For CNI-1493 studies, PM1 cells were infected with these viruses as before and incubated in the presence of CNI-1493 at concentrations of $0.5 \mu \mathrm{M}$ and $1.0 \mu \mathrm{M}$, or DMSO (control). The culture medium was replaced every 3 days. Cell viability (as measured by MTT assay) and p24 antigen levels were determined at days 6 and 12 after infection and again indicated no significant differences between the cultures. As shown in Figure 7A, the inhibitory effects of CNI-1493 on virus replication increased in a dose-dependent manner and reached max- imal inhibition rates, ranging from $72 \%$ to $96 \%$ for the tested viruses (BN8, BJ1, BM2, and BE4), at a concentration of 1.0 $\mu \mathrm{M}$. Notably, replication of "omni-resistant" viruses (BE4 and FE9), which were derived from clinical isolates unresponsive to the full array of nucleoside reverse transcriptase inhibitors, non-nucleoside reverse transcriptase inhibitors, and protease inhibitors, was also efficiently blocked (95-99\% inhibition of virus replication) by the DHS inhibitor CNI-1493 (Figure 7, A and B). The parallel monitoring of cell viability (by MTT assay) and replication of the FE9 isolate over a period of 3 weeks revealed the expected virus growth curves, demonstrating virus breakthrough in the unprotected culture, as opposed to efficient virus inhibition in the CNI-1493-protected cells (Figure 7B, graphs). The MTT assay demonstrated unchanged cell viability in the CNI-1493-treated culture, while the increase in virus replication resulted ultimately in cell death in the untreated control cells.

In summary, these data showed that replication of HIV-1 isolates that are resistant to multiple antiretroviral drugs is sensitive to treatment with inhibitors of hypusine formation.

\section{Discussion}

The data presented in this study suggest that human DHS is a novel and valuable drug target that can be exploited for the development of advanced antiretroviral therapies. Blocking of DHS activity, either by low-molecular weight compounds or by RNAi, demonstrated pronounced antiviral effects in cell lines and/or primary cells. Moreover, suppression of the formation of progeny viruses was observed in both $\mathrm{T}$ cell-tropic and macrophage-tropic laboratory strains, clinical isolates, and a series of multidrug-resistant viruses. Evidently, this anti-HIV effect is based on the inhibition of the viral regulatory protein Rev, which can be explained by the previous finding that the hypusine-containing protein eIF-5A participates in HIV-1 Rev-mediated trans-activation (9, 10, 30). Rev is an essential viral regulator that constantly shuttles between the nucleus and cytoplasm of host cells and primarily mediates the nucleocytoplasmic transport of incompletely spliced and unspliced viral mRNAs (8). In addition, Rev activity on the splicing, half-life, and translation of these transcripts has also been reported. Thus, Rev regulates the post-transcriptional processing of specific retroviral mRNAs.

DHS catalyzes the first reaction in a 2-step conversion of the inactive eIF-5A precursor to its activated hypusine-containing form (11). eIF-5A is unique because it is the only protein known in mammalian cells that contains this modification. Originally it was suggested that eIF-5A promotes the formation of the first peptide bond during protein synthesis (31, 32). However, subsequent studies have clearly demonstrated that eIF-5A is not involved in the initiation of general protein translation $(33,34)$. Thus, the exact in vivo activity of eIF-5A is still unknown. More recent findings in yeast suggested that eIF-5A is involved in the degradation of specific short-lived cellular messages and revealed a genetic link between eIF-5A and poly(A)binding protein $(35,36)$. Strikingly, the regulation of cellular mRNA turnover and that of cellular mRNA translation are intimately connected and appear to depend on tightly coupled nuclear and cytoplasmic processes (reviewed in refs. 37-39). Thus, shuttling proteins such as poly(A)-binding protein (40) link mRNA metabolism in the nuclear and cytoplasmic compartments. The previous findings that 
A
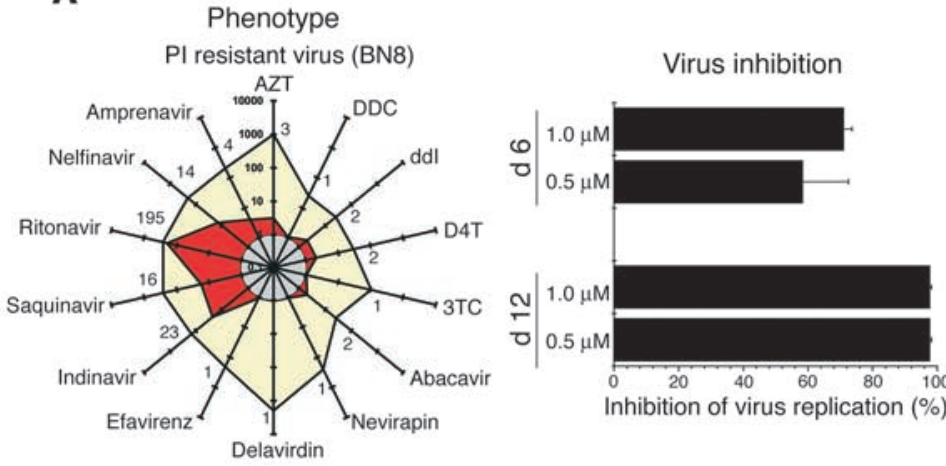

\section{Cellular toxicity}

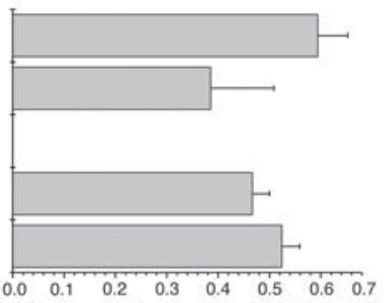

Inhibition of virus replication (\%) MTT assay (absorbance [560 nm])

NRTI resistant virus (BJ1)

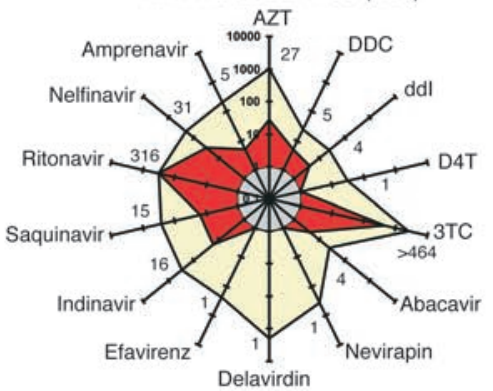

NNRTI resistant virus (BM2)

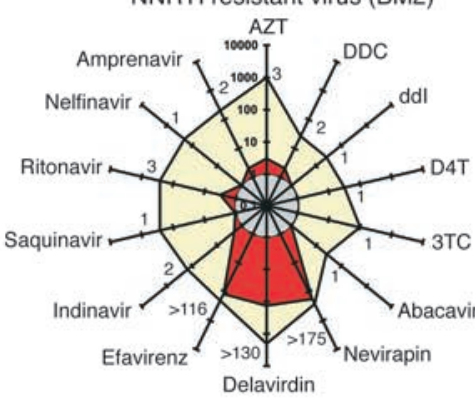

"Omni-resistant" virus (BE4)
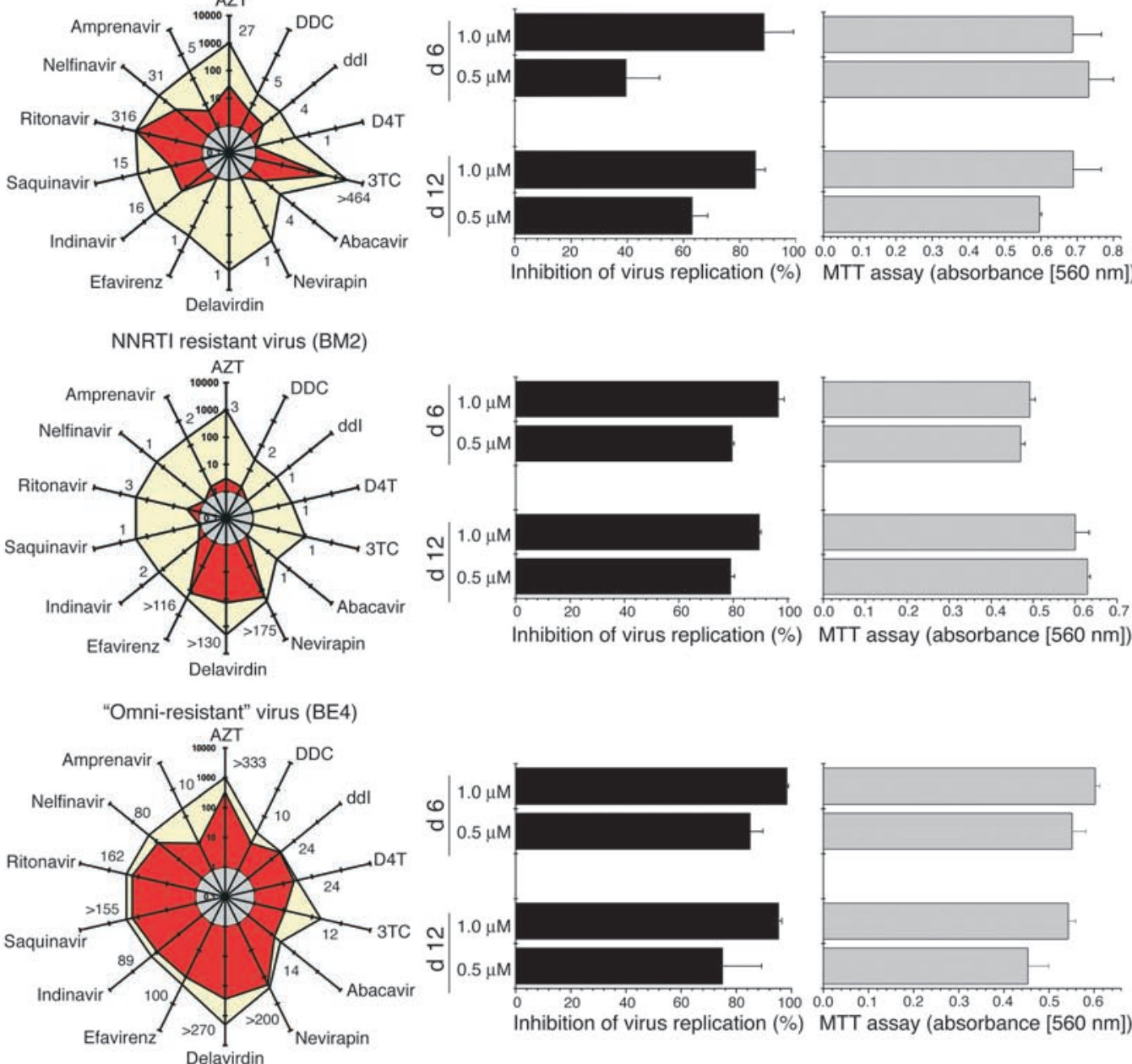

Inhibition of virus replication (\%) MTT assay (absorbance [560 nm])
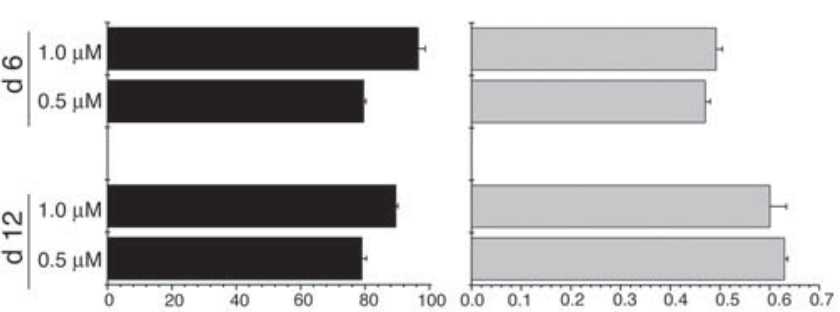

Inhibition of virus replication (\%) MTT assay (absorbance [560 nm])
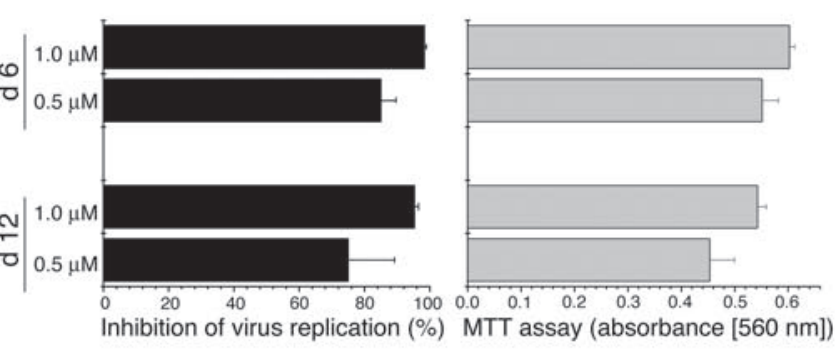

Figure 7

Inhibition of HAART-resistant HIV-1 isolates. PM1 cells were incubated for 6 days in the presence of $1.0 \mu \mathrm{M}$ $\mathrm{CNI}-1493$ or DMSO and then infected with various types of antiretroviral drug-resistant viruses. Results of the phenotypic drug sensitivity assay (red areas in the virograms; for details see text) are shown. The resistanceconferring mutations in the various viral genomes (genotypes), as determined by DNA sequencing, are summarized in the supplemental data section. (A) Infected cells were incubated in $\mathrm{CNI}-1493$ at concentrations of $1.0 \mathrm{uM}$ and $0.5 \mu \mathrm{M}$, or DMSO (control). Inhibition of virus replication (in percent) and drug toxicity (as measured by MTT assay) at days 6 and 12 are indicated in the right panels. (B) Three-week time course of inhibition of an "omniresistant" virus isolate (FE9) by $\mathrm{CNI}-1493$. p24 antigen level (p24Ag/CNI-1493 and p24Ag/DMSO control) and cell viability (MTT/CNI-1493 and MTT/DMSO control) were determined at days 6,9 , 12,16 , and 20 after infection (graphs). PI, protease inhibitor; NRTI, nucleoside reverse transcriptase inhibitor; NNRTI, non-nucleoside reverse transcriptase inhibitor; AZT, zidovudine; DDC, zalcitabine; ddl, didanosine; D4T, stavudine; 3TC, lamivudine.
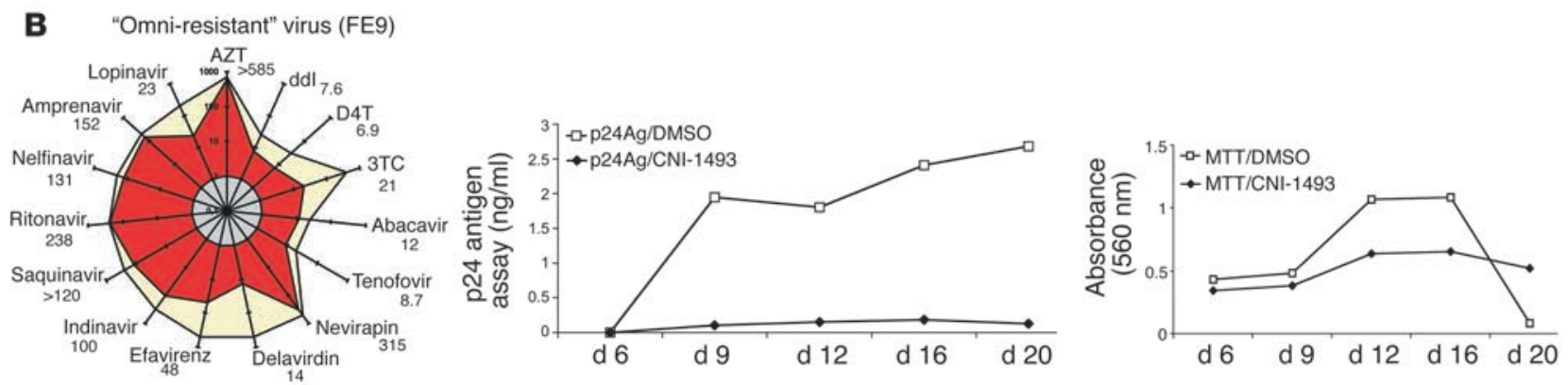
eIF-5A localizes in both the nucleus and the cytoplasm of mammalian cells (21) and can also be exported from the nucleus $(41,42)$ are intriguing and suggest that this unique protein indeed fulfills an activity in the metabolism of specific cellular RNAs. This notion is further supported by the finding that inhibition of the hypusine modification of eIF-5A causes the selective disappearance of certain mRNAs from polysomes (43).

The identification of the tetravalent guanylhydrazone CNI-1493 as a new and potent low-molecular weight inhibitor of DHS provides a novel opportunity to pharmaceutically interfere with cellular eIF-5A activity. CNI-1493 is currently undergoing phase II clinical trials for Crohn disease. This compound was originally described as an efficient inhibitor of macrophage activation that blocks the synthesis of proinflammatory cytokines (44). More recently it was reported that this drug also activates a neural anti-inflammatory pathway by stimulating the vagus nerve through an unknown mechanism (45). It is conceivable that these activities of CNI-1493 are connected to the so-far unknown anti-DHS activity of this compound. In contrast, previous studies have provided experimental evidence that CNI-1493 prevents proinflammatory cytokine production through inhibition of 38 MAPK phosphorylation, and this effect may also interfere with HIV-1 replication (19, 20). However, our DHS-specific RNAi data argue strongly against the notion that the anti-HIV effects observed can be attributed to the inhibition of p38 MAPK. In addition, there is also a striking discrepancy between the temporal kinetics of the reported inhibitory effects of CNI-1493. In tissue culture cells, a complete lack of phosphorylated p38 MAPK has been reported after 90 minutes of drug treatment (19), while, in sharp contrast, maximal antiviral effects were only observed after infected cells had been exposed to the compound for several days (Figure 4A). Moreover, the in vitro analysis of the p38 pathway kinases in a cell-free enzymatic assay revealed that the $50 \%$ inhibitory concentration $\left(\mathrm{IC}_{50}\right)$ of CNI-1493 for MAPK kinase 3 (MKK3), MKK6, and p38 MAPK is in the micromolar range (MKK3, $10 \mu \mathrm{M}$; MKK6, $2 \mu \mathrm{M}$; p38, $20 \mu \mathrm{M}$; A. Choidas, unpublished data), indicating a much higher effective inhibitory concentration $\left(\mathrm{EC}_{50}\right)$ within cellular systems. The $\mathrm{IC}_{50}$ with respect to virus suppression, however, appears to be in the submicromolar range (Figures 2-4).

Since DHS was identified as an attractive intracellular target for anti-HIV therapies, it was necessary to demonstrate that the antiviral effects of DHS inhibition did not result from general cellular toxicity. Previous studies have reported antiproliferative effects in certain tumor cell lines upon inhibition of hypusine modification of eIF-5A (14-16) as well as contradictory effects on apoptosis (46, 47). However, these studies used inhibitors (e.g., polyamine analogues, iron-chelating molecules) that, in addition to inhibiting hypusine formation, are likely to affect a number of additional aspects of cellular metabolism. Clearly, in the present study, the analysis of cell death, cell cycle progression, and general cytotoxicity demonstrated no adverse cellular effects of CNI-1493 at drug concentrations that significantly suppressed HIV-1 replication. These data indicate that a therapeutic window exists for HIV chemotherapy using novel types of DHS inhibitors.

The strategy to attack the viral life cycle by blocking cellular hypusine formation is also validated by 2 other independent studies. Feline immunodeficiency virus is, like HIV-1, a lentivirus. Its replication also depends on the Rev regulatory system. As demonstrated previously, treatment of cells with the DHS inhibitor 1.8-diaminooctane reduced viral replication in a dose-dependent manner and substantially decreased the level of Rev-regulated transcripts in the cytoplasm (48). Likewise, inhibition of the second hypusine-modification enzyme, the metalloenzyme deoxyhypusine hydroxylase, by metal-chelating compounds such as mimosine suppressed HIV-1 replication and reduced the association of unspliced gag mRNAs with polysomes (49).

In summary, the development of low-molecular weight compounds that inhibit DHS appears to be a promising approach to providing novel antiretroviral therapies. Such regimens may be advantageous in salvage therapies by achieving suppression of otherwise drug-resistant viruses.

\section{Methods}

Immunoprecipitation and 2-dimensional gel analyses. For detection of effects of DHS inhibitors on eIF-5A hypusine modification in vivo, $10^{7} \mathrm{Jurkat}$ cells were metabolically labeled for 12 hours using either $50 \mu \mathrm{Ci}\left[{ }^{14} \mathrm{C}\right]$ putrescine dihydrochloride (a metabolic spermidine precursor; $100 \mathrm{mCi} / \mathrm{mmol}$; Amersham Biosciences UK Limited) or $100 \mu \mathrm{Ci}\left[{ }^{35} \mathrm{~S}\right]$ cysteine $(600 \mathrm{Ci} / \mathrm{mmol}$; Hartmann Analytic GmbH) in the presence of $0.5 \mu \mathrm{M}$ or $1.0 \mu \mathrm{M}$ CNI-1493 or DMSO (solution control). Cells were pelleted, washed twice in PBS, and lysed in RIPA buffer ( $0.1 \%$ SDS, $1 \%$ Triton X-100, $1 \%$ sodium deoxycholate, $150 \mathrm{mM} \mathrm{NaCl}, 0.25 \mathrm{mM}$ PMSF, $1 \mathrm{mM}$ EDTA, $10 \mathrm{mM}$ Tris [pH 7.4]). Protein concentrations were determined by colorimetric protein assay (BioRad Laboratories), and equal protein amounts of the various radiolabeled cellular extracts were subjected to eIF-5A-specific immunoprecipitation analyses using rabbit polyclonal anti-eIF-5A antibody (50) and analyzed by $14 \%$ SDS-PAGE and autoradiography.

For 2-dimensional gel analysis of total cellular extracts, $10^{7} \mathrm{PM} 1$ cells were metabolically labeled as described above, using $10 \mu \mathrm{Ci}\left[{ }^{14} \mathrm{C}\right]$ spermidine trihydrochloride (112 $\mathrm{mCi} / \mathrm{mmol}$; Amersham Biosciences UK Limited) in the presence of $1.0 \mu \mathrm{M}$ CNI-1493 or DMSO. Gel analysis was performed as previously described (21).

$H I V-1$ infection experiments. HIV-1 infection experiments using the T celltropic (X4) strain NL4/3 (51), the macrophage-tropic (R5) strain BaL (52), or multidrug-resistant HIV-1 isolates were routinely performed using PM1 cells (virus laboratory strains and cells were obtained from the NIH AIDS Research and Reference Reagent Program). Cells were cultured in RPMI 1640 medium containing 10\% FCS (PanSystems GmbH) and antibiotics (penicillin and streptomycin). For HIV-1 infection, $5 \times 10^{7}$ cells were resuspended in $500 \mu \mathrm{l}$ culture medium without drugs and incubated at $37^{\circ} \mathrm{C}$ for 3 hours with $100 \mathrm{ng}$ of HIV-1 viral stocks. After infection, cells were washed twice with PBS without $\mathrm{Ca}^{2+}$ and $\mathrm{Mg}^{2+}$ to avoid false-positive $\mathrm{p} 24$ antigen determination. Cells were resuspended, and identical aliquots $\left(5 \times 10^{5}\right.$ per milliliter) of infected cells were further cultured in $5 \mathrm{ml}$ medium in the presence of DHS inhibitor (dissolved in DMSO) at various concentrations, or in medium with DMSO as control for the calculation of the inhibition of virus replication. At days 3, 6, and 9 after infection, the culture medium was changed and cells were split. Viability of the cells (as measured by MTT assay) and p24 antigen levels (as measured by ELISA; Innogenetics NV) were determined at days 6 and 12.

PBMCs from HIV-1-infected patients were isolated by Biocoll (Biochrom AG) gradient centrifugation. PBMCs $\left(1 \times 10^{6}\right.$ per milliliter $)$ were cultured in the presence of CNI-1493 or in DMSO (control diluent). The culture medium was changed every 3 days. Once a week, each culture was split 1:1, and $1 \times 10^{6}$ feeder PBMCs prepared from 4 healthy donors and $10 \mathrm{U} / \mathrm{ml}$ of recombinant IL-2 (Roche Diagnostics $\mathrm{GmbH}$ ) were added. Before addition to the cell cultures, $1 \times 10^{6}$ feeder PBMCs per milliliter were treated for 3 days with $4 \mu \mathrm{l}$ PHA-P ( $6 \mu \mathrm{g} / \mathrm{ml}$ phytohemagglutinin) and $1 \mu \mathrm{lPB}$ $(1 \mu \mathrm{g} / \mu \mathrm{l}$ polybrene; both from Sigma-Aldrich). At day 14 , viability of the PBMCs (as measured by trypan blue staining), cell count, and virus load were determined (INNOTEST HIV p24 antigen mAb from Innogenetics NV, or bDNA HIV-1 RNA 3.0 Assay from Bayer AG). 
Detection of proviral DNA. Integrated proviral DNA was assayed by PCR using $3 \mu$ g of genomic DNA and primer pairs complementary to the HIV-1 NL4/3 long-terminal repeat (LTR) and chromosomal Alu repeats: LTR forward/outer, 5'-GCTAACTAGGGAACCCACTGC-3'; LTR forward/nested, 5'-GCTTGCCTTGAGTGACCGATTG-3'; human Alu reverse/outer and reverse/nested, $5^{\prime}$-TGCTGGGATTACAGGCGTGAG-3'. The amplification profile involved 25 cycles of denaturation at $95^{\circ} \mathrm{C}$ for 1 minute, primer annealing at $58^{\circ} \mathrm{C}$ for 1 minute, and primer extension at $72^{\circ} \mathrm{C}$ for 4 minutes for the first round of PCR, followed by 35 cycles for the nested PCR.

Cell cultures, transfections, and assays. HeLa cells were maintained in DMEM containing 10\% FCS without antibiotics and transfected using Lipofectamine and Plus reagents according to the manufacturer's protocol (Invitrogen Corp.).

Rev-dependent rescue of provirus replication was analyzed by transient cotransfection of $5 \times 10^{5} \mathrm{HeLa}$ cells with $500 \mathrm{ng}$ of HIV-1 1 rev proviral DNA (25) and 250 ng of pBC12/CMV/SEAP (27) (transfection-efficiency control) together with $250 \mathrm{ng}$ of pcRev (53). Total input DNA was kept constant in all transfections by inclusion of the parental vector $\mathrm{pBC} 12 /$ CMV (54). At 60 hours after transfection, cellular extracts were prepared for Western analyses using antibodies recognizing HIV-1 p55 Gag (55) and $\alpha$-tubulin (Sigma-Aldrich). Cell supernatants were assayed for secreted alkaline phosphatase (SEAP) (27) and p24 antigen.

Rev trans-activation was investigated by cotransfection of $5 \times 10^{5} \mathrm{HeLa}$ cells with $600 \mathrm{ng}$ of pCMVgagLucRRE (26) and $300 \mathrm{ng}$ of pBC12/CMV/ $\beta$ Gal DNA (56), together with 300 ng of either pcRev (53) or the parental pBC12/CMV plasmid. At 48 hours after transfection, cellular lysates were prepared, and the levels of $\beta$-galactosidase (transfection-efficiency control) and luciferase were assayed by ELISA (Roche Diagnostics GmbH) or luminescence (Promega Corp.), respectively.

Likewise, Tat trans-activation was investigated by cotransfection of $5 \times 10^{5} \mathrm{HeLa}$ cells with $1.0 \mu \mathrm{g}$ of $\mathrm{pBC} 12 / \mathrm{HIV} / \mathrm{CAT}$ DNA (27) and $600 \mathrm{ng}$ of $\mathrm{pBC} 12 / \mathrm{CMV} / \beta \mathrm{Gal}$ DNA, together with $500 \mathrm{ng}$ of either pcTat (53) or the parental $\mathrm{pBC} 12 / \mathrm{CMV}$ plasmid. At 48 hours after transfection, cellular lysates were prepared, and the levels of $\beta$-galactosidase (transfectionefficiency control) and chloramphenicol acetyltransferase (CAT) were assayed by ELISA (Roche Diagnostics GmbH).

RNA analysis. For Northern blot analysis, $10^{8} \mathrm{PM} 1$ cells were infected with HIV-1 BaL as described above, washed twice in PBS, split 1:1, and cultured in the presence of either $0.8 \mu \mathrm{M} \mathrm{CNI}-1493$ or DMSO (solvent control). RNAs were isolated at day 7 after infection.

Cytoplasmic RNAs were prepared by isotonic lysis of the cells in the presence of $0.05 \% \mathrm{NP}-40$ as described previously (57). Total RNAs were isolated by direct lysis of the cells in $4 \mathrm{M}$ guanidine isothiocyanate and purified by centrifugation through a 5.7-M CsCl cushion using a TLA-100 rotor and a TLX ultracentrifuge (Beckman Coulter Inc.) for 2.5 hours at $420,000 \mathrm{~g}$ and $24^{\circ} \mathrm{C}$. The RNA pellet was dissolved in water, treated with phenol/chloroform/isoamylalcohol (25:24:1), and precipitated with ethanol. After centrifugation, RNA pellets were lyophilized and subsequently dissolved in water for further analysis.

Twenty-five micrograms of cytoplasmic and of total RNA samples was fractionated by electrophoresis through $1.2 \%$ formaldehyde agarose gels, transferred onto Hybond-N membranes (Amersham Biosciences UK Limited), and subjected to Northern analyses using HIV-1 U3 LTR-specific (5'-GGTGTGTAGTTCTGCCAATCAGGGAAGTAGCC-3') and U6 snRNA-specific (5'-GATTAGCATGGCCCCTGCGCAAGG-3') radiolabeled synthetic oligonucleotide probes. Intensities of specific bands were evaluated by phosphoimaging. To quantitatively compare unspliced and singly spliced cytoplasmic HIV-1 mRNA, the intensities of the multiply spliced class of HIV-1 mRNA (which accumulates in the cytoplasm in a Rev-independent fashion) were equalized, and the values for the unspliced and singly spliced RNA species were adjusted accordingly.
$R N A i$. For DHS knock-down, a siRNA duplex was used, which was generated by annealing of the RNA oligonucleotides 5'-CAUGGUGGACGUAUUGGUGdTdT-3' and 5'-CACCAAUACGUCCACCAUGdTdT-3' (Dharmacon Inc.) (23), targeting the nucleotides at positions 367-387 in the human DHS cDNA (58). As a negative control, the premade siRNA scramble II duplex (SDII; Dharmacon Inc.), which lacks complementary sequences in the human genome, was used.

HLCD4-CAT cells $\left(5 \times 10^{4}\right.$; obtained through the NIH AIDS Research and Reference Reagent Program from B.K. Felber and G.N. Pavlakis), which express the CD4 surface molecule, were cultured in DMEM, containing $10 \%$ FCS without antibiotics. Transfection with $60 \mathrm{pM}$ of RNA duplexes (DHS or SDII siRNA) was carried out using the Oligofectamine reagent according to the manufacturer's protocol (Invitrogen Corp.). Because of the relatively slow turnover of the DHS substrate eIF-5A, a DHS knock-down phenotype is expected to become apparent at approximately 1 week after siRNA treatment is initiated. Therefore, the respective cultures were transfected twice more over a period of 6 days before the cells were infected with HIV-1 $\mathrm{NL} 4 / 3$ (see above) or metabolically labeled using $\left[{ }^{14} \mathrm{C}\right]$ spermidine. At day 3 after infection, cells were subjected to MTT assay (Roche Diagnostics $\mathrm{GmbH}$ ), and virus replication was determined by p24 antigen assay (see above). Following RNA isolation with TRIzol reagent (Invitrogen Corp.), gene silencing was directly monitored by specific RT-PCR.

Analysis of cellular toxicity. Cell proliferation and cell viability were measured by standard MTT assay according to the manufacturer's protocol (Roche Diagnostics GmbH).

Patients. Patient 1 was a newly diagnosed asymptomatic and as-yet-untreated HIV-1-infected patient with a CD4 count of 373 per microliter and a viral load of 13,000 copies per milliliter. Patient 2 was an as-yet-untreated AIDS patient suffering from interstitial pneumonia with a strongly reduced CD4 count of 29 per milliliter and a viral load of 18,000 copies per milliliter. Patient 3 had developed a cerebral toxoplasmosis 3 years earlier and was treated by HAART. Despite treatment with abacavir, D4T, efavirenz, and nelfinavir, he had a low CD4 count of 181 per microliter and a detectable viral load of 3,500 copies per milliliter, which suggests partial viral drug resistance. Patient 4 was treated with liposomal daunorubicin because of a disseminated Kaposi sarcoma. Because of poor compliance, this patient showed a high viral load of 160,000 copies per milliliter and a low CD4 count of 69 per microliter despite combination therapy with ritonavir-boosted saquinavir, ddI, abacavir, efavirenz, and 3TC. The study was approved by the Ethics Committee of the medical faculty of the University Erlangen-Nürnberg.

Phenotypic resistance testing. Phenotypic HIV-1 drug sensitivity assays for reverse transcriptase and protease inhibitors were performed using recombinant viruses as previously described (28).

\section{Acknowledgments}

We thank Hauke Walter (University Erlangen-Nürnberg) for providing the panel of multidrug-resistant viruses and the respective phenotypic and genotypic data. We are indebted to Sarah L. Thomas for critical comments on the manuscript.

Received for publication April 22, 2004, and accepted in revised form November 2, 2004.

Address correspondence to: Joachim Hauber, Heinrich-Pette-Institute for Experimental Virology and Immunology, Martinistrasse 52, D-20251 Hamburg, Germany. Phone: 49-40-480-51-241; Fax: 49-40-480-51-184; E-mail: joachim.hauber@hpi.uni-hamburg.de.

Dorian Bevec's present address is: mondoBIOTECH Holding SA, Gentilino, Switzerland. 
1. Hammer, S.M., et al. 1997. A controlled trial of two nucleoside analogues plus indinavir in persons with human immunodeficiency virus infection and CD 4 cell counts of 200 per cubic millimeter or less. AIDS Clinical Trials Group 320 Study Team. N. Engl. J. Med. 337:725-733.

2. Gulick, R.M., et al. 1997. Treatment with indinavir zidovudine, and lamivudine in adults with human immunodeficiency virus infection and prior antiretroviral therapy. N. Engl. J. Med. 337:734-739.

3. Palella, F.J., Jr., et al. 1998. Declining morbidity and mortality among patients with advanced human immunodeficiency virus infection. HIV Outpatient Study Investigators. N. Engl. J. Med. 338:853-860.

4. Walsh, J.C., Jones, C.D., Barnes, E.A., Gazzard, B.G., and Mitchell, S.M. 1998. Increasing survival in AIDS patients with cytomegalovirus retinitis treated with combination antiretroviral therapy including HIV protease inhibitors. AIDS. 12:613-618.

5. Dybul, M., Fauci, A.S., Bartlett, J.G., Kaplan, J.E., and Pau, A.K. 2002. Guidelines for using antiretroviral agents among HIV-infected adults and adolescents. Ann. Intern. Med. 137:381-433.

6. Little, S.J., et al. 2002. Antiretroviral-drug resistance among patients recently infected with HIV. N. Engl. J. Med. 347:385-394.

7. Richman, D.D. 2001. HIV chemotherapy. Nature. 410:995-1001.

8. Pollard, V.W., and Malim, M.H. 1998. The HIV-1 Rev protein. Annu. Rev. Microbiol. 52:491-532.

9. Bevec, D., et al. 1996. Inhibition of HIV-1 replication in lymphocytes by mutants of the Rev cofactor eIF-5A. Science. 271:1858-1860.

10. Hofmann, W., et al. 2001. Cofactor requirements for nuclear export of Rev response element (RRE)and constitutive transport element (CTE)-containing retroviral RNAs. An unexpected role for actin. J. Cell Biol. 152:895-910.

11. Park, M.H., Wolff, E.C., and Folk, J.E. 1993. Hypusine: its post-translational formation in eukaryotic initiation factor $5 \mathrm{~A}$ and its potential role in cellular regulation. Biofactors. 4:95-104

12. Park, M.H., Wolff, E.C., and Folk, J.E. 1993. Is hypusine essential for eukaryotic cell proliferation? Trends Biochem. Sci. 18:475-479.

13. Jakus, J., Wolff, E.C., Park, M.H., and Folk, J.E. 1993. Features of the spermidine-binding site of deoxyhypusine synthase as derived from inhibition studies. Effective inhibition by bis- and monoguanylated diamines and polyamines. J. Biol. Chem. 268:13151-13159.

14. Park, M.H., Wolff, E.C., Lee, Y.B., and Folk, J.E. 1994. Antiproliferative effects of inhibitors of deoxyhypusine synthase. Inhibition of growth of Chinese hamster ovary cells by guanyl diamines. J. Biol. Chem. 269:27827-27832.

15. Shi, X.P., et al. 1996. Effects of N1-guanyl-1,7diaminoheptane, an inhibitor of deoxyhypusine synthase, on the growth of tumorigenic cell lines in culture. Biochim. Biophys. Acta. 1310:119-126.

16. Chen, Z.P., et al. 1996. Effects of inhibitors of deoxyhypusine synthase on the differentiation of mouse neuroblastoma and erythroleukemia cells. Cancer Lett. 105:233-239.

17. Sommer, M.-N., et al. 2004. Screening assay for the identification of deoxyhypusine synthase inhibitors. J. Biomol. Screen. 9:434-438.

18. Cohen, P.S., et al. 1996. CNI-1493 inhibits monocyte/macrophage tumor necrosis factor by suppression of translation efficiency. Proc. Natl. Acad. Sci. U. S. A. 93:3967-3971.

19. Wang, H., et al. 1998. Fetuin ( $\alpha 2$-HS-glycoprotein) opsonizes cationic macrophagedeactivating molecules. Proc. Natl. Acad. Sci. U. S. A. 95:14429-14434.

20. Cohen, P.S., et al. 1997. The critical role of p38 MAP kinase in T cell HIV-1 replication. Mol. Med.
3:339-346.

21. Klier, H., et al. 1995. Isolation and structural characterization of different isoforms of the hypusinecontaining protein eIF-5A from HeLa cells. Biochemistry. 34:14693-14702.

22. Hauber, J. 2001. Nuclear export mediated by the $\mathrm{Rev} / \mathrm{Rex}$ class of retroviral Trans-activator proteins. Curr. Top. Microbiol. Immunol. 259:55-76.

23. Elbashir, S.M., et al. 2001. Duplexes of 21-nucleotide RNAs mediate RNA interference in cultured mammalian cells. Nature. 411:494-498.

24. Sitaraman, S.V., Hoteit, M., and Gewirtz, A.T. 2003. Semapimod. Cytokine. Curr. Opin. Investig. Drugs. 4:1363-1368

25. Rimsky, L., et al. 1988. Functional replacement of the HIV-1 rev protein by the HTLV-1 rex protein. Nature. 335:738-740.

26. Daelemans, D., et al. 2002. A synthetic HIV-1 Rev inhibitor interfering with the CRM1-mediated nuclear export. Proc. Natl. Acad. Sci. U. S. A. 99:14440-14445.

27. Berger, J., Hauber, J., Hauber, R., Geiger, R., and Cullen, B.R. 1988. Secreted placental alkaline phosphatase: a powerful new quantitative indicator of gene expression in eukaryotic cells. Gene. 66:1-10.

28. Walter, H., et al. 1999. Rapid, phenotypic HIV-1 drug sensitivity assay for protease and reverse transcriptase inhibitors. J. Clin. Virol. 13:71-80.

29. Schmidt, B., et al. 2000. Simple algorithm derived from a geno-/phenotypic database to predict HIV-1 protease inhibitor resistance. AIDS. 14:1731-1738.

30. Katahira, J., et al. 1995. Effects of translation initiation factor eIF-5A on the functioning of human T-cell leukemia virus type I Rex and human immunodeficiency virus Rev inhibited trans dominantly by a Rex mutant deficient in RNA binding. J. Virol. 69:3125-3133.

31. Park, M.H. 1989. The essential role of hypusine in eukaryotic translation initiation factor 4D (eIF4D). Purification of eIF-4D and its precursors and comparison of their activities. J. Biol. Chem. 264:18531-18535.

32. Smit-McBride, Z., Schnier, J., Kaufman, R.J., and Hershey, J.W. 1989. Protein synthesis initiation factor eIF-4D. Functional comparison of native and unhypusinated forms of the protein. J. Biol. Chem. 264:18527-18530.

33. Kang, H.A., Schwelberger, H.G., and Hershey, J.W.B. 1993. Effect of initiation factor eIF-5A depletion on cell proliferation and protein synthesis. In Protein synthesis and targeting in yeast. A.J.P. Brown, M.F. Tuite, and J.E.G. McCarthy, editors. Springer-Verlag. Berlin, Germany. 123-129.

34. Kang, H.A., and Hershey, J.W. 1994. Effect of initiation factor eIF-5A depletion on protein synthesis and proliferation of Saccharomyces cerevisiae. J. Biol. Chem. 269:3934-3940.

35. Zuk, D., and Jacobson, A. 1998. A single amino acid substitution in yeast eIF-5A results in mRNA stabilization. ЕМBO J. 17:2914-2925.

36. Valentini, S.R., Casolari, J.M., Oliveira, C.C., Silver, P.A., and McBride, A.E. 2002. Genetic interactions of yeast eukaryotic translation initiation factor 5A (eIF5A) reveal connections to poly(A)-binding protein and protein kinase $\mathrm{C}$ signaling. Genetics. 160:393-405.

37. Wilusz, C.J., Wormington, M., and Peltz, S.W. 2001. The cap-to-tail guide to mRNA turnover. Nat. Rev. Mol. Cell Biol. 2:237-246.

38. Guhaniyogi, J., and Brewer, G. 2001. Regulation of mRNA stability in mammalian cells. Gene. 265:11-23.

39. Wilkinson, M.F., and Shyu, A.B. 2002. RNA surveillance by nuclear scanning? Nat. Cell Biol. 4:E144-E147.
40. Afonina, E., Stauber, R., and Pavlakis, G.N. 1998. The human poly(A)-binding protein 1 shuttles between the nucleus and the cytoplasm. J. Biol. Chem. 273:13015-13021.

41. Rosorius, O., et al. 1999. Nuclear pore localization and nucleocytoplasmic transport of eIF-5A: evidence for direct interaction with the export receptor CRM1. J. Cell Sci. 112:2369-2380.

42. Lipowsky, G., et al. 2000. Exportin 4: a mediator of a novel nuclear export pathway in higher eukaryotes. EMBO J. 19:4362-4371.

43. Hanauske-Abel, H.M., et al. 1995. Detection of a sub-set of polysomal mRNAs associated with modulation of hypusine formation at the G1-S boundary. Proposal of a role for eIF-5A in onset of DNA replication. FEBS Lett. 366:92-98.

44. Bianchi, M., et al. 1996. Suppression of proinflammatory cytokines in monocytes by a tetravalent guanylhydrazone. J. Exp. Med. 183:927-936.

45. Bernik, T.R., et al. 2002. Pharmacological stimulation of the cholinergic antiinflammatory pathway. J. Exp. Med. 195:781-788.

46. Lee, Y., Kim, H.K., Park, H.E., Park, M.H., and Joe, Y.A. 2002. Effect of N1-guanyl-1,7-diaminoheptane, an inhibitor of deoxyhypusine synthase, on endothelial cell growth, differentiation and apoptosis. Mol. Cell. Biochem. 237:69-76.

47. Caraglia, M., et al. 2003. The eukaryotic initiation factor $5 \mathrm{~A}$ is involved in the regulation of proliferation and apoptosis induced by interferon-alpha and EGF in human cancer cells [erratum 2003, 134:173]. J. Biochem. (Tokyo). 133:757-765.

48. Hart, R.A., Billaud, J.N., Choi, S.J., and Phillips, T.R. 2002. Effects of 1,8-diaminooctane on the FIV Rev regulatory system. Virology. 304:97-104.

49. Andrus, L., et al. 1998. Antiretroviral effects of deoxyhypusyl hydroxylase inhibitors: a hypusinedependent host cell mechanism for replication of human immunodeficiency virus type 1 (HIV-1). Biochem. Pharmacol. 55:1807-1818.

50. Schatz, O., et al. 1998. Interaction of the HIV-1 rev cofactor eukaryotic initiation factor $5 \mathrm{~A}$ with ribosomal protein L5. Proc. Natl. Acad. Sci. U. S. A. 95:1607-1612.

51. Adachi, A., et al. 1986. Production of acquired immunodeficiency syndrome-associated retrovirus in human and nonhuman cells transfected with an infectious molecular clone. J. Virol. 59:284-291.

52. Gartner, S., et al. 1986. The role of mononuclear phagocytes in HTLV-III/LAV infection. Science. 233:215-219.

53. Malim, M.H., et al. 1988. Immunodeficiency virus rev trans-activator modulates the expression of the viral regulatory genes. Nature. 335:181-183.

54. Cullen, B.R. 1986. Trans-activation of human immunodeficiency virus occurs via a bimodal mechanism. Cell. 46:973-982.

55. Chesebro, B., Wehrly, K., Nishio, J., and Perryman, S. 1992. Macrophage-tropic human immunodeficiency virus isolates from different patients exhibit unusual V3 envelope sequence homogeneity in comparison with T-cell-tropic isolates: definition of critical amino acids involved in cell tropism. J. Virol. 66:6547-6554.

56. Ruhl, M., et al. 1993. Eukaryotic initiation factor $5 \mathrm{~A}$ is a cellular target of the human immunodeficiency virus type 1 Rev activation domain mediating trans-activation. J. Cell Biol. 123:1309-1320.

57. Greenberg, M.E., and Ziff, E.B. 1984. Stimulation of 3T3 cells induces transcription of the c-fos proto-oncogene. Nature. 311:433-438.

58. Bevec, D., et al. 1996. Molecular characterization of a cDNA encoding functional human deoxyhypusine synthase and chromosomal mapping of the corresponding gene locus. FEBS Lett. 378:195-198. 